\title{
EFFECTS OF FACE IMAGES AND FACE PAREIDOLIA ON CONSUMERS' RESPONSES TO PRINT ADVERTISING
}

Gianluigi Guido, (corresponding author)

Department of Management, Economics, Mathematics, and Statistics

University of Salento, Ecotekne Campus, Via per Monteroni, 73100 Lecce, Italy +390832 298601, gianluigi.guido@unisalento.it

Marco Pichierri, Department of Management, Economics, Mathematics, and Statistics University of Salento, Ecotekne Campus, Via per Monteroni, 73100 Lecce, Italy marco.pichierri@unisalento.it

Giovanni Pino, Department of Management, Economics, Mathematics, and Statistics University of Salento, Ecotekne Campus, Via per Monteroni, 73100 Lecce, Italy giovanni.pino@unisalento.it

Rajan Nataraajan, Department of Economics, Auburn University Auburn, AL 36849, natarra@auburn.edu 


\title{
EFFECTS OF FACE IMAGES AND FACE PAREIDOLIA ON CONSUMERS' RESPONSES TO PRINT ADVERTISING
}

\begin{abstract}
The present research investigates whether print advertisements featuring faces (i.e., "face ads") or face-like images (i.e., "pareidolian ads") are better able to capture consumer attention than ads that do not include such elements. In two studies, the research examined the effects of exposing consumers to print ads containing faces or pareidolian images for short time lapses $(0.5,1$, and 3 seconds). The results show that both ad types capture viewers' attention and are more frequently recognized than advertisements that do not feature faces or face-like objects. Moreover, both face ads and pareidolian ads increase brand recognition and ad preference. The theoretical and operational implications are discussed.
\end{abstract}

Keywords: Faces, pareidolia, orienting response, attention, ad preference, ad recognition, brand recognition.

\section{Management Slant}

- Ads featuring human faces and "face-like" (i.e., pareidolian) images capture greater attention and preference than other ads in short time lapses.

- With increasing time exposure, the attention-grabbing capacity of face and pareidolian ads gradually decreases.

- $\quad$ Face and pareidolian ads lead to greater ad and brand recognition than other ads. 


\section{INTRODUCTION}

Today's consumers cope with an overabundance of advertising stimuli. Every day, a regular consumer will see an average of 360 commercial messages across the five main media (TV, radio, Internet, newspapers, and magazines) (Johnson, 2014). In the U.S. alone, the TV airs an average of 38 ads every minute (Nielsen, 2014). This number significantly exceeds consumers' information processing capacities: Of the 360 ads that they are exposed to daily, consumers may only notice $42 \%$ of them and recall far fewer (Johnson, 2014). In an attempt to break through the clutter, advertisers try to use a wide variety of attention-grabbing devices (Guido, 2001) — from noticeable logos to high color contrast, or creative stimuli aimed at eliciting emotions (Ipsos, 2016; Millward Brown, 2009, 2017).

Nevertheless, consumers generally devote scant attention to ad messages. They normally look at print advertisements for less than two seconds (Hill, 2010) and at online advertisements for one-third of a second (Nielsen and Pernice, 2010). This means that, in an increasingly crowded arena, the competition for consumers' attention is played on smaller and smaller time frames. Consequently, advertisers need to know the mechanisms underlying consumers' attention and thereby increase the chances that messages will be processed.

Consumers manage the plethora of commercial information by paying selective attention to specific stimuli (e.g., Desimone and Duncan, 1995). In this respect, faces might play a pivotal role, as they serve as biologically and socially significant visual stimuli that convey primal information about social interaction (Ellis and Young, 1998). Faces are so highly relevant that they can automatically capture attention better than objects such as cars, houses, clothes, and foods (Ro, Russell, and Lavie, 2001; VanRullen, 2006). The human mind is so attentive to faces that people can sometimes see them in non-face images (Kato and Mugitani, 2015) — an illusory phenomenon known as pareidolia, from the Greek "para" (beside or beyond) and "eidolon" (form, or image). Both faces and face-like images may 
automatically recruit people's attention through an orienting response mechanism (Tomalski, Csibra, and Johnson, 2009), that is an involuntary reflexive reaction to a sudden or meaningful stimulus (e.g., Greenwald and Leavitt, 1984).

Although advertising communications could benefit from utilizing faces, there have been no significant empirical assessments of whether advertisements featuring faces (i.e., face ads) and those featuring face-like images (i.e., pareidolian ads) have the potential to stand out in a cluttered advertising environment. To fill this gap, this research investigates whether these two ad types are better able to capture consumers' attention and impact their memory than advertisements that lack facial elements. More specifically, it investigates the effects that arise from consumers' orienting response to face and pareidolian ads within short time lapses. Ultimately, this study explores whether facial and pareidolian stimuli can increase consumers' attention and preference toward ads, as well as recognition of ads and brands in print advertisements.

\section{ORIENTING RESPONSE}

When humans encounter stimuli that convey meaningful messages, they reflexively experience a boost in attention (Lang, Bradley, and Cuthbert, 1997). Such an involuntary reflexive reaction to a sudden or significant stimulus is known as the orienting response (cf. Greenwald and Leavitt, 1984; Sokolov, 1990) and corresponds to "focal attention being directed toward a stimulus" (Greenwald and Leavitt, 1984, p. 584). This built-in sensitivity results in a "reflexive response to an environmental stimulus, such that there is a transient orientation of the individual to the stimulus" (MacKay-Brandt, 2011, p. 1830). However, orienting response does not necessarily coincide with an overt behavioral reaction, as it "serves to potentiate information processing and to prepare or facilitate a rapid behavioral 
response to the eliciting stimulus (even if such action is not always undertaken)" (Nieuwenhuis, De Geus, and Aston-Jones, 2011, p. 162).

A number of studies in the field of cognitive psychology (e.g., Graham and Hackley, 1991; Öhman, Hamm, and Hugdahl, 2000) have shown that both novel and meaningful stimuli elicit the orienting response. Novel stimuli are unknown or unexpected stimuli, whereas meaningful stimuli (e.g. faces) are those that convey information that is relevant to an individual and perhaps emotionally charged. Because individuals have limited cognitive resources (Lang, 2000), they are inclined to focus on salient stimuli that automatically activate involuntary attention (Guido, 2001; Lang, Bradley, and Cuthbert, 1997). In turn, the orienting response increases individuals' memory of the information embedded in such stimuli (cf. Deffenbacher et al., 2004). In particular, Greenwald and Leavitt (1984) suggested that orienting responses can be elicited by familiar stimuli that are specially significant to the individual (e.g. faces; Artuso, Palladino, and Ricciardelli, 2015; Ro, Friggel, and Lavie, 2007). In this vein, psychological research highlighted "the existence of a bias to preferentially orient attention toward faces at the expense of other non-face stimuli" (Tomalski, Csibra, and Johnson, 2009; p. 569).

Despite its practical relevance for advertising strategies, the orienting response has not been thoroughly explored by marketing research, particularly in terms of how it might determine consumers' responses to advertising messages featuring faces.

\section{FACES AS SIGNIFICANT VISUAL STIMULI}

Faces are arguably the most biologically and socially significant visual stimuli in the human environment: for this reason, they have a special ability to capture attention and deliver meaningful information. Previous studies have argued that this adaptive process creates an attentional bias for faces (Frischen, Eastwood, and Smilek, 2008). Faces rapidly 
and efficiently transmit information about other people's intentions, as well as their feelings about past, present, and future events (e.g., Small and Verrochi, 2009).

Because of their socio-biological significance, faces receive enhanced processing in the competition for attention (Dekowska, Kuniecki, and Jaskowski, 2008; Hershler and Hochstein, 2005; Rakover and Cahlon, 2001), which makes them ideal candidates for automatic processing (Öhman, 2002). Ultimately, the psychological research posits that faces typically capture attention more easily than other visual stimuli (Palermo and Rhodes, 2007; VanRullen, 2006; Weaver and Lauwereyns, 2011). Faces induce also stronger involuntary responses: in large scenes containing a face among other objects, the very first saccades tend to be directed to the face (Cerf et al., 2008; Honey, Kirchner, and Van Rullen, 2008), and, in general, individuals categorize faces much faster than other objects (Pegna et al., 2004).

Across several contexts, scholarly research has shown that faces generally help attract attention. In the field of retail marketing, it has been shown that mannequins with a headand hence a face-lead to higher intention to purchase the merchandise displayed on them than headless mannequins (Lindström et al., 2016). In the field of marketing communication, it has been shown that Instagram photos featuring faces are about $40 \%$ more likely to receive "likes" than photos without faces (Bakhshi, Shamma, and Gilbert, 2014). Meanwhile, existing research in the advertising field, has shown that online banners containing faces may capture greater attention than banners without faces (Sajjacholapunt and Ball, 2014) and that advertising content is more easily recalled when advertisements include faces (Droulers and Adil, 2015a); in addition, faces may affect consumers' attitudes toward advertising and their purchasing intentions (Xiao and Ding, 2014).

Although both advertising practice and the psychological literature (Cerf, Frady, and Koch, 2009) suggest that individuals focus on faces to the detriment of other stimuli, this issue remains under-investigated. In particular, the advertising literature has not yet assessed 
the differential ability of "face" ads versus "no-face" ads to capture consumer attention, which merits further research (cf. Droulers and Adil, 2015a; Sajjacholapunt and Ball, 2014; Xiao and Ding, 2014).

\section{PAREIDOLIA AND THE ILLUSORY PERCEPTION OF FACES}

Humans tend to perceive faces — as well as body parts, animal shapes, or other familiar images - in clouds, rocks, planetary landforms and other places where they do not actually exist (Shelley, 2015). This phenomenon, known as pareidolia (Chalup, Hong, and Ostwald, 2010; Hong et al., 2013; Liu et al., 2014), induces people to recognize familiar forms in unrelated visions of real things. This sensitivity to face-like patterns derives from an unconscious tendency to seek familiar images in novel perceptual inputs (Gosselin and Schyns, 2003; Rieth et al., 2011), as well as from the social importance that humans innately ascribe to faces (Liu et al., 2014).

Among all pareidolian forms, face pareidolia is the most widespread because of humans' natural predisposition for detecting faces (Martinez-Conde and Macknik, 2012). Unlike most other visual objects, which are processed analytically, faces are processed "configurally"that is, they are perceived as non-decomposed wholes rather than as a combination of independent parts (Richler and Gauthier, 2014; Rossion, 2013). All faces have a basic Tshaped configuration — consisting of two eyes, a nose, and a mouth — that represents a "template" for rapidly differentiating faces from other visual stimuli in the surrounding environment (Tsao and Livingstone, 2008). Because of their reliance on this template, humans also tend to see faces in any object characterized by the T-shaped configuration. Hence why stylized sequences of typographical symbols, such as emoticons, are immediately recognized as faces (Chalup, Hong, and Ostwald, 2010). 
Although some companies have already constructed products around a T-shaped configuration (e.g., Celine's handbags), and have occasionally included pareidolian images in their print advertisements, advertising research has not yet assessed whether such images are truly superior to other types of advertising images in terms of their attention-grabbing and processing abilities. In the past few decades, marketing research has focused on anthropomorphism - namely the attribution of human-like characteristics to nonhuman objects (e.g., Guido and Peluso, 2015) — and found that products that incorporate human features (e.g., human-face cookies) induce increased attention and deeper processing (Epley, Waytz, and Cacioppo, 2007), as well as influence consumers' attitudes and intentions towards said products (Hart and Royne, 2017; Hur, Koo, and Hofmann, 2015). Advertising research has particularly found that ads featuring anthropomorphic presentations may foster brand liking (Delbaere, McQuarrie, and Phillips, 2011) and influence consumers' intentions (Hart and Royne, 2017). Nevertheless, existing literature has not specifically focused on advertising messages that feature pareidolian images; thus, we lack an understanding of their ability to capture viewers' attention and influence their processing.

\section{RESEARCH HYPOTHESES}

Although the use of face and pareidolian images is common in advertising practice (Keaveney et al., 2012), there is very little evidence that advertisements featuring faces and face-like images have a superior ability to capture consumer attention. Drawing from visual perception literature, which stresses that faces activate an immediate reaction (Cerf, Frady, and Koch, 2009) and induce more involuntary orienting responses than other visual stimuli (Hershler and Hochstein, 2005; VanRullen, 2006), we hypothesize that this process may also occur for ads featuring faces and pareidolian images. Formally: 
H1a: Face ads attract more attention than no-face ads.

H1b: Pareidolian ads attract more attention than non-pareidolian ads.

At the same time, Sambeth et al. (2004) showed that repeated or lengthened exposures to a stimulus reduces the magnitude of this orienting response. Such an effect explains why individuals' attention to a particular stimulus fades as their exposure time increases (Zimmer, 2006). Based on these arguments, we hypothesize that:

H2a: With increasing exposure time, consumer attention to face ads decreases.

H2b: With increasing exposure time, consumer attention to pareidolian ads decreases.

Individuals generally recognize a stimulus more easily when it captures their attention (cf. Ohyama and Watanabe, 2010). As faces receive priority in the competition for selective attention, it is possible that individuals may process faces, and their associated information, more readily than other stimuli. Translating this idea into marketing, previous research shows that brand recognition, i.e. consumer's ability to confirm prior exposure to a brand when given said brand as a cue (Keller, 1993), improves when the associated ad garners more attention (e.g., Lombardot, 2007). Hence, when an ad ensnares a person's attention, s/he is more likely to correctly identify the associated brand as attention strengthens memory (Schomaker and Wittmann, 2017). Moreover, recent studies suggest that pareidolia may produce a similar positive effect on individuals' memory processes. In particular, Kato and Mugitani (2015) established that once individuals perceive pareidolian faces, they tend to pay attention to them, even when knowing they are illusory. More broadly, Rieth et al. (2011) noticed that people's perception of novel objects as being similar to familiar objects 
favorably influences their memorization and subsequent detection. Therefore, it seems plausible to hypothesize that:

H3a: Face ads activate greater brand recognition than no-face ads.

H3b: Pareidolian ads activate greater brand recognition than non-pareidolian ads.

Higher levels of attention can improve not only consumers' brand memory, but also their likelihood of recognizing the ad later (cf. Aribarg, Pieters, and Wedel, 2010). Ad recognition refers to viewers' capacity for identifying a certain ad among other ads after prior exposure. We expect that ads featuring faces or pareidolian images will be more salient in viewers' minds than other types of advertisements, and thus recognized more easily. Formally:

H4a: Face ads produce greater ad recognition than no-face ads.

H4b: Pareidolian ads produce greater ad recognition than non-pareidolian ads.

Finally, the orienting response mechanism might significantly affect consumers' preferences for various print advertisements (Nielsen, Shapiro, and Mason, 2010). When choosing between two options, people prefer alternatives that require them to orient their gaze (Simion and Shimojo, 2007). Because faces and face-like objects capture individuals' attention, we hypothesize that:

H5a: Face ads are preferred over no-face ads. 
H5b: Pareidolian ads are preferred over non-pareidolian ads.

\section{STUDY 1A}

\section{Face Ads Stimuli}

We selected a random set of real print ads promoting fashion-branded products. We chose this category because fashion advertisements normally feature endorsers, and hence faces. We grouped advertisements into pairs of a similar branded product (e.g., two ads about handbags from the same brand) in order to avoid the confounding effects of brand preference, product preference, or executional style. To this end, two independent judges (who identified ads with the same products and brands) pre-screened the pairs and then applied the Pixolution ImageSorter ${ }^{\mathrm{TM}}$ software, which classifies images based on their visual similarity and color weight. This step allowed us to mitigate the potential confound of color preference when seeing the two ads side-by-side.

Each pair included only one advertisement containing a face. We controlled for facial dimension by including an equivalent number of large faces (i.e., faces whose size was half or more of the advertisement) and small faces. To rule out the possible influence of sexual stimuli (cf. Severn, Belch, and Belch, 1990) and facial expressions (Neumann and Strack, 2000), the judges selected the advertisements that lacked such stimuli and featured only neutral facial expressions (e.g., Ilicic, Kulczynski, and Baxter, 2016; Small and Verrochi, 2009). The judges eliminated approximately $10 \%$ of the initial pools of images, resolving any disagreement through discussion. We controlled for endorsers' gaze direction by including an equal number of faces with either direct gaze (i.e., facing towards the ideal interlocutor) or averted gaze (i.e., laterally shifted gaze) in the pool of ads (cf. Droulers and Adil, 2015b; Hutton and Nolte, 2011). The final set of ads featured an equal number of male and female 
Caucasian endorsers with similar levels of attractiveness. We decided to use real advertisements to maximize the study's external validity.

A total of 96 print advertisements were split into 48 pairs, with each pair referring to the same fashion brand. Next, the 48 pairs were randomly divided into three sets, each containing an equal number of ads featuring small vs. large faces, male vs. female endorsers, and endorsers with direct vs. averted gaze. To avoid habituation effects, we inserted six pairs of advertisements without faces or any chromatic similarities into each set, using random number tables to determine their position. Thus, each set of advertisements comprised 22 pairs. Each pair of images was copied and pasted into a Microsoft PowerPoint ${ }^{\mathrm{TM}}$ presentation. Within each set, we placed pairs in a random order, using random number tables to determine the face ad's position (left or right) on each slide so as to mitigate the confounding influence of side preference.

\section{Procedure}

Four researchers approached potential participants in public spaces (cafeterias, libraries, sport centers, and retail stores) in a medium-sized city. They invited subjects to partake in a research study in exchange for a coupon redeemable at a local consumer electronics store. A total of 322 people $\left(\mathrm{M}_{\text {Age }}=26.13 \mathrm{yrs}, \mathrm{SD}_{\mathrm{Age}}=9.68\right)$, equally distributed by gender, agreed to participate. They were given a pre-arranged schedule and instructed to meet with a researcher in a laboratory at the local university campus. Participants entered the laboratory one-by-one, received a printed questionnaire, and sat down before a video projector displaying the PowerPoint ${ }^{\mathrm{TM}}$ presentation and its three sets of stimuli. Participants saw each pair (see Figure 1A for examples) for different time lapses: 


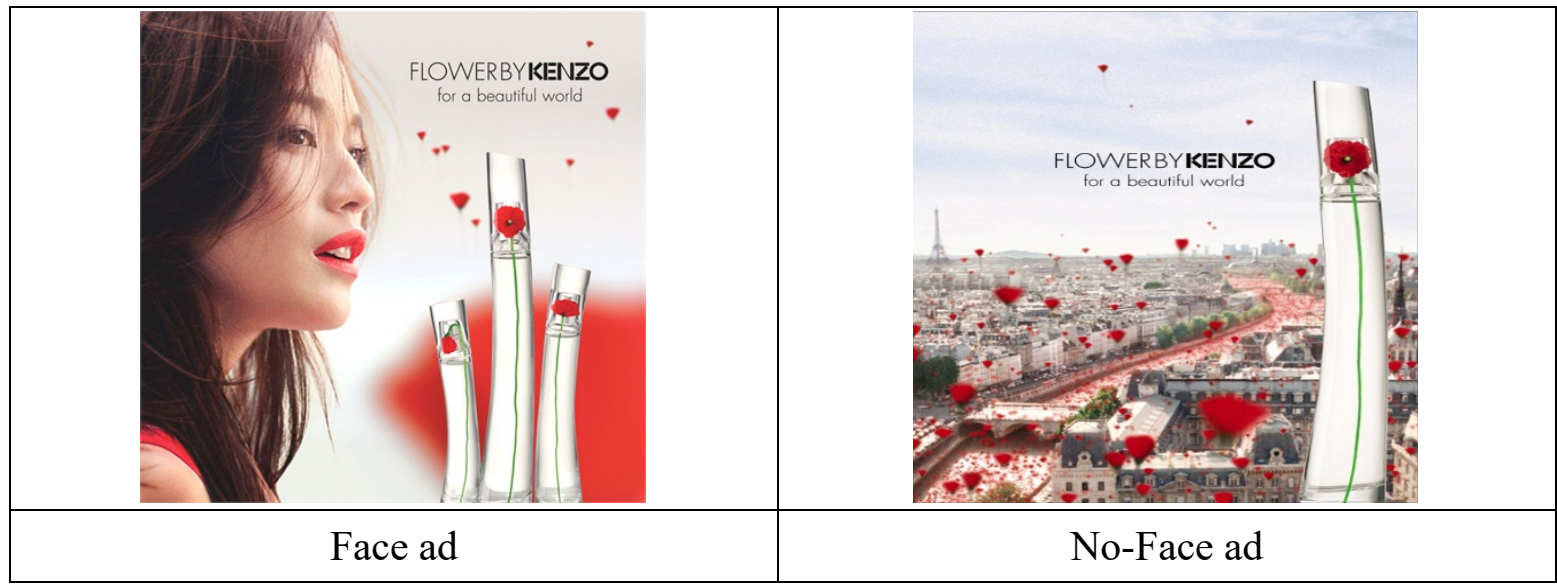

Figure 1A Example of a pair of advertisements shown to participants of Study 1A.

The pairs in Set 1 were displayed for 0.5 seconds; in Set 2 for 1 second, and in Set 3 for 3 seconds. The series of treatment conditions were completely counterbalanced: We presented the three time exposure conditions $(0.5,1,3 \mathrm{sec}$.$) in every possible sequence to rule out$ possible time-related threats and order effects. For each of the 22 pairs of ads included in each set, the researchers asked participants to first indicate, using their questionnaire, which of the two displayed advertisements more immediately attracted their attention. Afterward, participants watched an entertaining, two-minute video about curious cats on the same projector screen in order to not only divert their attention from the study's real purpose, but also to create a time gap between the ad exposure and the recognition tasks. Once the video concluded, participants completed the rest of the questionnaire by identifying the brands featured in the displayed advertisements using a list of 30 brands printed on the questionnaire. Fifteen of those brands matched the 15 pairs of advertisements featuring a face ad (five pairs for each set); the other 15 brands matched the 15 pairs of advertisements that did not feature a face ad (five pairs for each set).

Afterward, the questionnaire asked participants to identify the displayed advertisements using three recognition sheets (one for each set). The sheet for each respective set contained: eight ads (featuring faces) that participants saw during the experiment; eight ads (without 
faces) that appeared during the experiment; and eight "filler" ads (four with faces and four without faces) that were not displayed during the experiment. For each set, participants had two minutes to mark the images that they thought corresponded to the advertisements displayed earlier in the study.

In a final step, participants viewed the three sets of advertisements a second time. After seeing each pair for a fixed time lapse (five seconds), they indicated on the questionnaire whether they preferred the ad displayed on the left or right.

\section{Results}

Attention-getting capacity. We performed chi-square tests on each pair of ads to check whether face ads attracted significantly more attention than no-face ads. The results revealed that, for 44 of the 48 pairs presented ( $91.7 \%$ of total), face ads attracted more attention than no-face ads $(p s<.05)$, thus supporting H1a. Specifically, face ads attracted more attention than no-face ads for 15 of the 16 pairs $(94 \%$ of total) in the 0.5 -second condition; 16 of the 16 pairs $(100 \%$ of total $)$ in the 1 -second condition, and 13 of the 16 pairs $(81 \%$ of total $)$ in the $3-$ second condition.

Subsequently, we averaged the data regarding the number of times a participant reported being attracted to face ads and no-face ads. Then, we conducted a one-way repeated measures ANOVA to compare the scores derived for the face ads in the three conditions. The results indicated that time exposure exerted a significant treatment effect. 
Specifically, participants' attention toward face ads decreased as the exposure time increased; Wilks' Lambda $=.63, F(2,320)=92.73, p<.001$, partial $\eta^{2}=.37 ; \mathrm{M}_{\text {Set } 1}=11.75$, $\mathrm{SD}=2.70 ; \mathrm{M}_{\mathrm{Set}} 2=11.26, \mathrm{SD}=2.64, \mathrm{M}_{\mathrm{Set} 3}=9.53, \mathrm{SD}=3.29$. Hence, H2a was supported. The post-hoc tests with Bonferroni adjustment confirmed that the three treatments differed from one another $(p<.001)$.

Brand recognition. Participants recognized brands associated with pairs featuring face ads better than those featuring no-face ads. The average brand recognition associated with face ads equaled $1.76(\mathrm{SD}=1.15)$ for Set 1 (i.e., about $67 \%$ of all the recognized brands), 2.53 $(\mathrm{SD}=1.36)$ for Set 2 (i.e., about $63 \%$ of all the recognized brands), and $2.63(\mathrm{SD}=1.22)$ for Set 3 (i.e., about $67 \%$ of all the recognized brands). Thus, the results supported H3a.

Ad recognition. Participants recognized face ads better than no-face ads. Specifically, the mean recognition of face ads equaled $3.82(\mathrm{SD}=1.95 ; 62 \%$ of correctly recognized ads) in the 0.5 -second condition, 4.84 ( $\mathrm{SD}=1.92 ; 64 \%$ of correctly recognized ads) in the 1 -second condition, and 5.13 ( $\mathrm{SD}=1.82 ; 63 \%$ of correctly recognized ads) in the 3 -second condition. Hence, H4a was supported.

Ad preference. In order to test H5a, we summed the frequencies of participants' expressed preferences for one of the advertisements in each pair. To check for significant differences in frequency distribution, we performed chi-square tests for each pair of ads. Results showed that participants preferred face ads to no-face ads in 31 of the 48 pairs ( $p s<.05,64.6 \%$ of total), thus confirming H5a. More specifically, they preferred face ads to no-face ads for 11 of the 16 pairs $(68.8 \%$ of total) in the 0.5 -second condition of the attention task; 10 of the 16 
pairs $(62.5 \%$ of total $)$ in the 1 -second condition, and 10 of the 16 pairs $(62.5 \%$ of total $)$ in the 3-second condition.

\section{STUDY 1B}

To rule out the possibility that results of Study 1A stem from differences in the executional style of the ads rather than the intended experimental manipulation (face presence vs. absence), and test our hypotheses on a different sample in order to ensure that our results do not vary across age groups (Study 1A's mean age was low), we ran a new study with 135 people $\left(\mathrm{M}_{\mathrm{Age}}=29.87 \mathrm{yrs}, \mathrm{SD}_{\mathrm{Age}}=9.98\right)$. To this aim, sixteen print advertisements promoting fashion-branded products, published on popular magazines, were randomly selected following criteria similar to those of Study 1A (no sexual stimuli; only neutral facial expressions). Ads were then manipulated by creating a copy of each of the sixteen images in which we removed only the model's face. Then, sixteen pairs of advertisements, with each pair including the original ad (face-ad) versus its no-face version (see Figure 1B for an example), were inserted in a Qualtrics-based questionnaire (also in this case, to avoid habituation effects, we inserted six pairs of advertisements without faces or any chromatic similarities). The questionnaire included the same experimental tasks as in Study 1A (random number tables were used to determine the face ad's position), while participants were randomly assigned to one of the three time conditions $(0.5 \mathrm{sec} ., 1 \mathrm{sec} ., 3 \mathrm{sec}$.). 


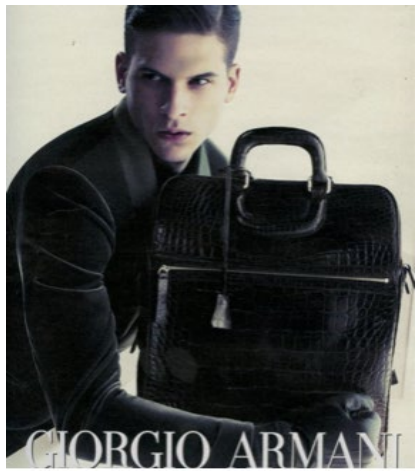

Face ad

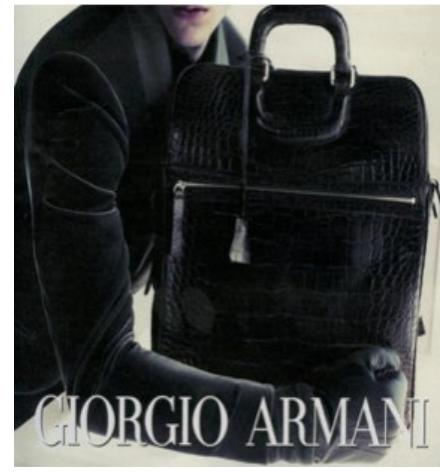

No-Face ad

Figure 1B Example of a pair of advertisements shown to participants of Study 1B.

Results revealed that, again, face ads attracted more attention than no-face ads, thus providing further support to H1a. Specifically, face ads attracted more attention than no-face ads for 16 of the 16 pairs $(100 \%$ of total) in all the three time exposure conditions $(0.5,1$, and 3 seconds). A one-way ANOVA revealed that participants' attention toward face ads decreased as the exposure time increased, $F(2,132)=4.38, p<.05$, partial $\eta^{2}=.06$. Furthermore, post-hoc comparisons using the Tukey HSD test indicated that attention score in the 0.5 -second condition $(\mathrm{M}=14.00, \mathrm{SD}=2.33$ ) differed significantly from the 1 -second condition $(\mathrm{M}=12.70, \mathrm{SD}=2.55)$ and the 3 -second condition $(\mathrm{M}=12.29, \mathrm{SD}=3.70)$.

The average brand recognition associated with face ads equaled $5.18(\mathrm{SD}=2.72)$ in the 0.5 -second condition (i.e., about $79 \%$ of all the recognized brands), $5.37(\mathrm{SD}=2.30$ ) in the 1 second condition (i.e., about $81 \%$ of all the recognized brands), and $4.98(\mathrm{SD}=2.27)$ in the 3-second condition (i.e., about $79 \%$ of all the recognized brands). Thus, the results provided further support to H3a. Participants also recognized face ads better than no-face ads. Specifically, the mean recognition of face ads equaled $6.39(\mathrm{SD}=1.81 ; 57 \%$ of correctly recognized ads) in the 0.5 -second condition, $6.70(\mathrm{SD}=1.39 ; 59 \%$ of correctly recognized ads) in the 1 -second condition, and 6.47 ( $\mathrm{SD}=1.40 ; 57 \%$ of correctly recognized ads) in the 3-second condition, further supporting H4a. Finally, participants preferred face ads to no-face 
ads in 16 of the 16 pairs ( $100 \%$ of total), in all the three time exposure conditions, further confirming H5a.

Finally, in order to rule out possible age-related differences, we compared two subsamples of respondents by splitting the whole sample according the median value of age (Median = 28). A MANOVA revealed no significant between-group differences in the considered dependent measures $(p>.05)$, thus excluding possible age-related differences in responses.

\section{STUDY 2}

\section{Pareidolian Ads Stimuli}

Following the same criteria as before, we selected 36 pairs of advertisements, with each pair including an ad with a pareidolian element — namely, the image of a product or other elements resembling a face - taken from a random set of print advertisements covering a range of product categories (food, cars, etc.). These 36 pairs were then randomly divided into three sets of 12 pairs each. To avoid habituation effects, we supplemented each set with four pairs of non-pareidolian ads featuring no chromatic similarity, using random number tables to determine their position. Thus, each final set consisted of 16 pairs. Finally, we copied and pasted all pairs into a PowerPoint ${ }^{\mathrm{TM}}$ presentation, organizing them in the same way as in Study 1 (see Figure 2 for an example). 


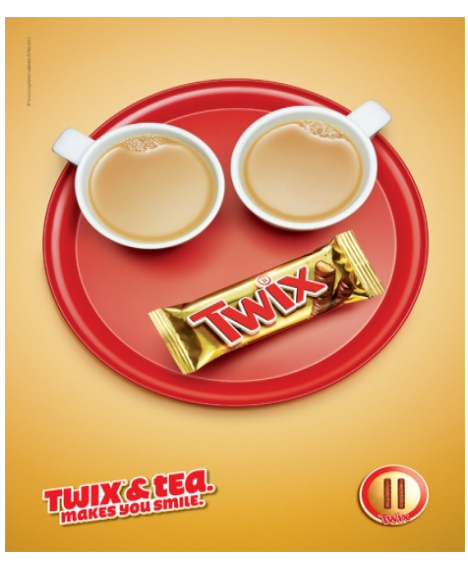

Pareidolian ad

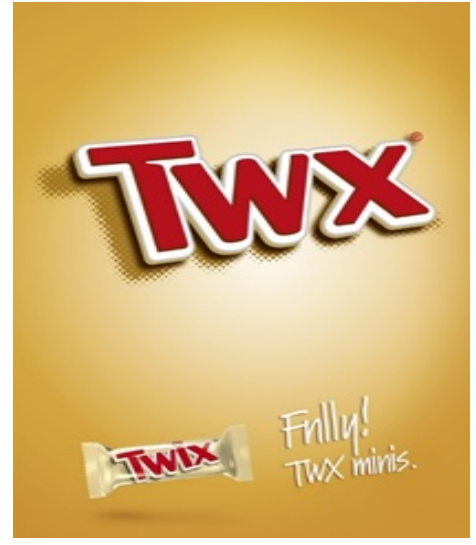

Non-pareidolian ad

Figure 2 Example of a pair of advertisements shown to participants of Study 2.

\section{Procedure}

Four researchers gathered a consumer sample $\left(\mathrm{M}_{\text {Age }}=26.71 \mathrm{yrs}, \mathrm{SD}_{\text {Age }}=9.91,48 \%\right.$ females $)$, using the same procedure as in Study 1A. Ultimately, 154 individuals participated in the laboratory experiment, viewing the three sets of stimuli for pre-defined time lapses (same as in Study 1A). In this case, the brand recognition task covered 24 brands: 12 brands were associated with the pairs of advertisements featuring a pareidolian ad (four pairs for each set); the other 12 brands were associated with the pairs featuring non-pareidolian ads (four pairs for each set). Like in Study 1A, participants indicated their ad recognition on provided sheets (one for each set). Each sheet displayed miniaturized versions of 18 advertisements: six were the same pareidolian ads displayed during the experiment; six were the same non-pareidolian ads displayed during the experiment; and the remaining six were advertisements that were not displayed during the experiment. 


\section{Results}

Attention-getting capacity. Chi-square tests revealed that, for 29 of the 36 pairs $(80.6 \%$ of total), the pareidolian ads attracted significantly more attention than the non-pareidolian ads $(p s<.05)$, thus supporting H1b. Specifically, the pareidolian ads attracted more attention than the non-pareidolian ads for 11 of the 12 pairs (i.e., $91.6 \%$ of total) in the 0.5 -second condition; 10 of the 12 pairs (i.e., $83.3 \%$ of total) in the 1 -second condition, and 8 of the 12 pairs (i.e., $66.7 \%$ of total) in the 3 -second condition.

A one-way repeated measures ANOVA compared the mean attention scores in the three treatment conditions. The results showed a significant treatment effect for time exposure, $F$ $(2,152)=39.66, p<.001$, partial $\eta^{2}=.34 . \mathrm{M}_{\text {Set } 1}=8.67, \mathrm{SD}=1.91 ; \mathrm{M}_{\text {Set } 2}=8.05, \mathrm{SD}=2.04 ;$ $\mathrm{M}_{\text {Set } 3}=7.03, \mathrm{SD}=2.13$, thus supporting $\mathrm{H} 2 \mathrm{~b}$. The post-hoc tests, performed with Bonferroni adjustment of the significance level, showed that the three treatments differed from one another $(p<.01)$.

Brand recognition. Participants recognized brands associated with pairs featuring pareidolian ads better than those featuring non-pareidolian ads. More precisely, the average brand recognition score for the pareidolian ads equaled $1.44(\mathrm{SD}=.83)$ for Set 1 (i.e., about $72 \%$ of all recognized brands); $2.27(\mathrm{SD}=.97)$ for Set 2 (i.e., about $68 \%$ of all recognized brands), and $2.45(\mathrm{SD}=1.05)$ for Set 3 (i.e., about $71 \%$ of all recognized brands). Thus, $\mathrm{H} 3 \mathrm{~b}$ was supported.

Ad recognition. Participants recognized pareidolian ads better than non-pareidolian ads. Specifically, the mean recognition score of the pareidolian ads equaled $3.19(\mathrm{SD}=1.59 ; 62 \%$ of correctly recognized advertisements) in the 0.5 -second condition, 3.85 ( $\mathrm{SD}=1.39 ; 62 \%$ of correctly recognized advertisements) in the 1 -second condition, and 4.25 (SD $=1.60 ; 61 \%$ of 
correctly recognized advertisements) in the 3-second condition. Hence, the results supported H4b.

Ad preference. Chi-square tests revealed that, for 23 of the 36 pairs of ads ( $63.9 \%$ of total), participants preferred the pareidolian ads to the non-pareidolian ads ( $p s<.05)$, thus validating H5b. Specifically, participants preferred the pareidolian ads in 7 of the 12 pairs $(58.3 \%$ of total) in the 0.5 -second condition of the attention task; 9 of the 12 pairs ( $75 \%$ of total) in the 1 -second condition, and 7 of the 12 pairs $(58.3 \%$ of total) in the 3 -second condition.

\section{GENERAL DISCUSSION}

The results highlight that face and pareidolian ads attract greater attention than other ads. Given short exposure times, individuals instinctively seek faces in advertising because of the orienting response mechanism, which stems from the superior significance of faces, emotionally and biologically.

However, exposure time represents a caveat. For both face and pareidolian ads, participants' attention decreased as exposure time increased. This result suggests that a longer exposure mitigates the attention-grabbing effect of faces. Given more time, viewers are probably able to observe other ad features and hence evaluate the whole ad, without necessarily focusing on faces.

The results also show that both face and pareidolian ads lead to greater brand recognition than advertisements that lack facial elements. Furthermore, our research ascertained that both faces and pareidolian images drive greater ad recognition. Indeed, participants recognized face and pareidolian ads better than the alternative advertisements, regardless of the length of exposure. These results are in line with prior literature on orienting response according to which, if a task elicits orienting responses, memory for the informative aspects of a stimulus 
is enhanced (Deffenbacher et al., 2004). Finally, the research demonstrated that consumers prefer both face and pareidolian ads to other types of ads. This result aligns with previous literature (cf. Bradley, 2008; Nielsen, Shapiro, and Mason, 2010; Simion and Shimojo, 2007) and leads us to suppose that the orienting response might have significantly affected ad preference formation.

\section{IMPLICATIONS FOR ADVERTISING PRACTICE}

Consumers are commonly exposed to several ads through the same media vehicles, some of which deliver advertising messages for very short times (seconds or even fractions of seconds) —e.g., electronic billboards, internet banners, and the like (cf. Keller, 1991; Nielsen and Pernice, 2010), and this exposure dilutes the effect of advertising (cf. Kent and Allen, 1994). Thus, it is crucial for marketers to understand how to capture consumer attention.

In light of this situation, this research sought to assess the effects produced by faces and face-like images in print advertising. The obtained results show that face and pareidolian ads attract viewers' attention more easily than other advertisements. Generally categorized in about $100 \mathrm{~ms}$, faces are detected at least twice as fast as many other stimuli (Palermo and Rhodes, 2007; Pegna et al., 2004). Our findings reflect this competitive advantage, and suggest that the orienting response to faces might have produced positive cascading effects in terms of brand recognition, ad recognition, and ad preference.

Advertisers should exploit the power of faces in their communicational campaigns. Our results may be especially useful for designing print advertisements, billboards, banners, or any other type of advertising commonly observed for a short period of time (Smit, Neijens, and Stuurman, 2006). For instance, face and pareidolian ads could be placed in airports, train stations, or other public settings where consumers witness myriad ads and thus devote very little attention to them (Huang, Koster, and Borchers, 2008). The visual saliency of faces- 
that is, their ability to stand out and attract attention - might significantly increase the amount of attention that consumers pay to billboard advertising, for example. This higher attention could, in turn, positively affect consumers' ad preferences.

The use of faces could help marketers overcome consumers' tendency to overlook banners (the so-called banner blindness phenomenon), which is widely recognized as a major problem in advertising (Hervet et al., 2010). Furthermore, by incorporating faces and pareidolian images in advertising messages, marketers could increase consumers' recognition of the advertised brands and preference for the advertised messages. Some companiesranging from car manufacturers (e.g., BMW, Mercedes, etc.) to food producers (e.g., Oreo, Nespresso, etc.) — have already begun leveraging this strategy, mainly using face ads to attract viewers' attention and pareidolian ads to stimulate consumers' imagination regarding their products.

\section{LIMITATIONS AND FUTURE RESEARCH}

As regards the limitations of this research, we note, first of all, that, in a limited number of comparisons face and pareidolian ads did not work as hypothesized, which was probably due to the fact that faces and face-like elements were, in some cases, not clearly identifiable. Additionally, it is worth noting that although experimental manipulation used in Study 1B might appear unrepresentative of the earlier study treatments (which opposed face ads to product shots sans figures), this manipulation technique was the only one that allowed us to control for all possible differences in executional style while using real print advertisements. Second, across the studies, the considered advertisements covered a broad range of products (e.g., handbags, foods, watches, etc.); however, we did not assess whether the product category moderates the effects of face presence in advertising. Future research could 
investigate this possibility, looking at whether faces improve consumers' evaluations of the advertised product (e.g., in terms of perceived reliability).

Third, we tested face and pareidolian ads in comparison with non-face and nonpareidolian ads. Therefore, future research could investigate whether our results hold also when face and pareidolian ads are seen individually. Future research could also explore comparisons between face and pareidolian advertisements. If the two were equally effective, advertising strategists could reduce expenditures (e.g., royalties) by using pareidolian ads. Moreover, scholars could assess whether exposure to face and pareidolian ads unconsciously influences consumers' willingness to buy the advertised products (cf. Janiszewski, 1993), and if the length of exposure moderates this potential effect.

Furthermore, because our studies were conducted in a controlled environment, future research could also replicate our findings in real contexts (e.g., shopping malls; outdoor advertising) in order to increase our studies' ecological validity. Finally, we should note that both samples involved Western consumers. Thus, future research could determine whether our findings translate to different cultural contexts - for instance, in a country where the presence of faces (especially of female endorsers) in print advertisements may be uncommon or even prohibited. 


\section{REFERENCES}

Aribarg, A., R. Pieters, and M. Wedel. "Raising the BAR: Bias Adjustment of

Recognition Tests in Advertising." Journal of Marketing Research 47, 3 (2010): 387-400.

Artuso, C., P. Palladino, and P. Ricciardelli. "Social Updating: The Role of Gaze Direction in Updating and Memorizing Emotional Faces." Social Cognition 33, 6 (2015): $543-561$.

BAKHShi, S., D. A. Shamma, and E. Gilbert. "Faces Engage Us: Photos with Faces Attract more Likes and Comments on Instagram." In Proceedings of the 2014 ACM Conference on Human Factors in Computing Systems, pp. 965-974.

Bradley, M. M. "Natural Selective Attention: Orienting and Emotion." Psychophysiology 46, 1 (2008): 1-11. doi:10.1111/j.1469-8986.2008.00702.

CERF, M., E. P. FrAdy, and C. KoCH. "Faces and Text Attract Gaze Independent of the Task: Experimental Data and Computer Model." Journal of Vision 9 (2009): 1-15.

Cerf, M., J. Harel, W. EinhäUser, W., and C. Koch. "Predicting Human Gaze Using LowLevel Saliency Combined with Face Detection." In Advances in Neural Information Processing Systems 20, J.C. Platt, D. Koller, Y. Singer, and S.T. Roweis, eds. pp. 241-248, 2008.

Chalup, S. K., K. Hong, and M. J. Ostwald. "Simulating Pareidolia of Faces for Architectural Image Analysis." International Journal of Computer Information Systems and Industrial Management Applications 2 (2010): 262-78.

DefFenbacher, K.A., B.H. Bornstein, S.D. Penrod, and E.K. MCGorty. “A MetaAnalytic Review of the Effects of High Stress on Eyewitness Memory". Law and Human Behavior 28, 6 (2004): 687-706.

DeKOWSKA, M., M. KUNIECKI, and P. JASKOWSKI. "Facing Facts: Neuronal Mechanisms of Face Perception.” Acta Neurobiologiae Experimentalis 68, 2 (2008): 229-52.

Delbaere, M., E. F. McQuarrie, \& B.J. Phillips. "Personification in Advertising." Journal of Advertising 40 (2011): 121-130.

Desimone, R., and J. Duncan. "Neural Mechanisms of Selective Visual Attention." Annual Review of Neuroscience 18, 1 (1995): 193-222.

Droulers, O., and S. AdIL. "Could Face Presence in Print Ads Influence Memorization?" Journal of Applied Business Research 31, 4 (2015a): 1403-1408.

Droulers, O., and S. AdIL. "Perceived Gaze Direction Modulates Ad Memorization." Journal of Neuroscience, Psychology, and Economics 8, 1 (2015b): 15-26.

Ellis, H. D., and A. W. Young. "Faces in Their Social and Biological Context." In Face and Mind, A.W. Young, ed. pp. 67-95. Oxford University Press, New York, NJ, 1998. 
Epley, N., A. Waytz, and J. T. CACioppo. "On Seeing Human: A Three-Factor Theory of Anthropomorphism." Psychological Review 114, 4 (2007): 864-86.

Frischen, A., J. D. EASTwood, and D. SMILEK. "Visual Search for Faces with Emotional Expressions." Psychological Bulletin 134, 5 (2008): 662-76.

Gosselin, F., and P. G. SchYns. "Superstitious Perceptions Reveal Properties of Internal Representations.” Psychological Science 14, 5 (2003): 505-509.

Graham, F. K., and S. A. Hackley. "Passive and Active Attention to Input." In Handbook of Cognitive Psychophysiology, J.R. Jennings, and M.G.H.Coles, eds. pp. 251-356.

Chichester: Wiley, 1991.

Greenwald, A. G., and C. LeAvitt, C. "Audience Involvement in Advertising: Four Levels." Journal of Consumer Research 11, 1 (1984): 581-92.

GuIDO, G. The Salience of Marketing Stimuli. Kluwer Academic Publishers, 2001.

Guido, G., and Peluso, A. M. "Brand Anthropomorphism: Conceptualization, Measurement, and Impact on Brand Personality and Loyalty". Journal of Brand Management 22, 1 (2015): $1-19$.

HaRT, P., and M. B. RoYNe. "Being Human: How Anthropomorphic Presentations Can Enhance Advertising Effectiveness". Journal of Current Issues \& Research in Advertising, (2017): in press.

Hershler, O., and S. Hochstein. "At First Sight: A High-Level Pop Out Effect for Faces." Vision Research 45, 13 (2005): 1707-1724.

Hervet, G., K. GuÉrard, S. Tremblay, S., and M. S. Chtourou. "Is Banner Blindness Genuine? Eye Tracking Internet Text Advertising." Applied Cognitive Psychology 25, 5 (2011): 708-16.

HILL, D. About Face: The Secrets of Emotionally Effective Advertising. Kogan Page Publishers, 2010.

Hong, K., S. K. Chalup, R. King, and M. J. Ostwald. "Scene Perception Using Pareidolia of Faces and Expressions of Emotion." In Computational Intelligence for Creativity and Affective Computing (CICAC), 2013 IEEE Symposium (pp. 79-86). IEEE, 2013.

Honey, C., H. Kirchner, and R. VanRullen (2008). "Faces in the Cloud: Fourier Power Spectrum Biases Ultrarapid Face Detection.” Journal of Vision 8, 12 (2008): 1-13.

HuAng, E. M., A. Koster, and J. BorChERS. "Overcoming assumptions and uncovering practices: When does the public really look at public displays?." In Pervasive Computing, J. Indulska et al., eds., pp. 228-243, Springer Berlin Heidelberg, 2008.

Hur, J. D., M. Koo, and W. Hofmann. "When Temptations Come Alive: How Anthropomorphism Undermines Self-Control." Journal of Consumer Research 42, 2 (2015): $340-58$. 
Hutton, S. B., and S. Nolte. "The Effect of Gaze Cues on Attention to Print Advertisements." Applied Cognitive Psychology 25, 6 (2011): 887-892.

Ilicic, J., A. Kulczynski, and S. BAXTER. "How a Smile Can Make a Difference: Enhancing the Persuasive Appeal of Celebrity Endorsers." Journal of Advertising Research (2016). doi: 10.2501/JAR-2016-003.

IPSOS (2016, Oct.). "Diamonds are no longer forever". Retrieved April 2017 from: http://www.ipsos-na.com/dl/pdf/knowledge-

ideas/advertising/IpsosConnect_POV_DiamondsAreNoLongerForever.pdf

JANISZEWSKI, C. "Preattentive Mere Exposure Effects." Journal of Consumer Research 20, 3 (1993): 376-92.

JOHNSON, S. (2014, Sept). "New research shed light on daily ad exposures." Retrieved March 2015 from SJ Insights: http://sjinsights.net/2014/09/29/new-research-sheds-light-on-daily-adexposures.

Kato, M., and R. Mugitani. "Pareidolia in Infants". PloS one, 10, 2 (2015). doi: 10.1371/journal.pone.0118539.

Keaveney, S.M., A. Herrmann, R. Befurt, J. R. Landwehr. "The Eyes Have it: How a Car's Face Influences Consumer Categorization and Evaluation of Product Line Extensions." Psychology \& Marketing 29, 1 (2012): 36-51.

KeLLER, K. L. "Memory and Evaluation Effects in Competitive Advertising Environments." Journal of Consumer Research 17, 4 (1991): 463-76.

KELLER, K. L. "Conceptualizing, Measuring, and Managing Customer-Based Brand Equity." Journal of Marketing 57, 1 (1993): 1-22.

Kent, R. J., and C. T. Allen. "Competitive Interference Effects in Consumer Memory for Advertising: The Role of Brand Familiarity.” The Journal of Marketing 58, 3 (1994): 97-105.

LANG, A. "The Limited Capacity Model of Mediated Message Processing.” Journal of Communication 50, 1 (2000): 46-70.

LANG, P. J., M. M., BradLeY, and B.N. CuthBERT. "Motivated attention: affect, activation, and action." In Attention and Orienting: Sensory and Motivational Processes J. Lang, R. F. Simons, and M. T. Balaban, eds. pp. 97-135. Hillsdale, NJ: Lawrence Erlbaum Associates, 1997.

Lindström, A., H. Berg, J. Nordfält, A. L. Roggeveen, and D. Grewal. "Does the Presence of a Mannequin Head Change Shopping Behavior?" Journal of Business Research 69, 2 (2016): 517-24.

LiU, J., J. Li, L. Feng, L. Li, J. Tian, and K. LeE. "Seeing Jesus in Toast: Neural and Behavioral Correlates of Face Pareidolia." Cortex 53 (2014): 60-77. 
LOMBARDOT, É. "Nudity in Advertising: What Influence on Attention-Getting and Brand Recall?" Recherche et Applications en Marketing 22, 4 (2007): 23-41.

MACKAY-BRANDT, A. “Orienting Response.” In Encyclopedia of Clinical Neuropsychology (pp. 1830-1831). Springer New York, 2011.

MARTINEZ-COnde, S., and S. L. MACKNIK. “A Faithful Resemblance.” Scientific American Mind 23, 4 (2012): 19-21.

Millward BROWN (2009). "Should My Advertising Stimulate an Emotional Response?" Millward Brown: Knowledge Point. Retrieved April 10, 2017, from http://www.wpp.com/ /media/sharedwpp/readingroom/marketing/millward_brown_emotiona 1_response.pdf.

MiLlWARD BROWN (2017, February 22). "When creativity pays.” Retrieved April 10, 2017, from http://www.millwardbrown.com/global-navigation/blogs/post/mbblog/2017/02/22/when-creativity-pays.

Neumann, R., and F. STRACK. "Mood Contagion: The Automatic Transfer of Mood between Persons." Journal of Personality and Social Psychology 79, 2 (2000): 211-23.

NiELSEN (2014, May). “Advertising and audiences: State of the media.”. Retrieved September 2015 from:

http://www.nielsen.com/content/dam/nielsenglobal/jp/docs/report/2014/Nielsen_Advertising _ and_\%20Audiences\%20Report-FINAL.pdf.

Nielsen, J. H., S. A. Shapiro, and C. H. MAson. "Emotionally and Semantic Onsets: Exploring Orienting Attention Responses in Advertising". Journal of Marketing Research 47, 6 (2010): 1138-1150.

Nielsen, J., and K. PeRniCE. Eyetracking Web Usability. New Riders, 2010.

Nieuwenhuis, S., E.J. De Geus, and G. Aston-Jones. "The Anatomical and Functional Relationship between the P3 and Autonomic Components of the Orienting Response." Psychophysiology 48, 2 (2011): 162-175.

ÖHMAN, A. "Automaticity and the Amygdala: Nonconscious Responses to Emotional Faces." Current Directions in Psychological Science 11 (2002): 62-66.

Öhman, A., A. Hamm, A., and K. Hugdahl. "Cognition and the Autonomic Nervous System: Orienting, Anticipation, and Conditioning." In Handbook of Psychophysiology (2nd ed), J. T. Cacioppo, L.G. Tassinary, and G. G. Bernston, eds. pp. 533-575. Cambridge: Cambridge University Press, 2000.

Ohyama, J., and K. WatanaBe. "Exogenous Temporal Cues Enhance Recognition Memory in an Object-Based Manner." Attention, Perception, \& Psychophysics 72, 8 (2010): 21572167.

Palermo, R., and G. Rhodes. "Are You Always on My Mind? A Review of how Face Perception and Attention Interact." Neuropsychologia 45, 1 (2007): 75-92. 
Pegna, A. J., A. Khateb, C. M. Michel, and T. LAndis. "Visual Recognition of Faces, Objects, and Words Using Degraded Stimuli: Where and When It Occurs." Human Brain Mapping 22, 4 (2004): 300-11.

RAKOver, S. S., and B. CAHLON. Face Recognition: Cognitive and Computational Processes. Advances in Consciousness Research (Vol. 31). Amsterdam: John Benjamins Publishing, 2001.

RichleR, J. J., and I. GAUTHIER. "A Meta-Analysis and Review of Holistic Face Processing." Psychological Bulletin 140, 5 (2014): 1281-1302.

Rieth, C.A., K. LeE, J. Lui, J. TiAn, and D. E. Huber. "Faces in the Mist: Illusory Face and Letter Detection." i-Perception 2, 5 (2011), 458-76. doi:10.1068/i0421

Ro, T., C. Russell, and N. LAVIE. "Changing Faces: A Detection Advantage in the Flicker Paradigm.” Psychological Science 12, 1 (2001): 94-99.

Rossion, B. "The Composite Face Illusion: A Whole Window into Our Understanding of Holistic Face Perception.” Visual Cognition 21, 2 (2013): 139-253.

Sambeth, A., J. H. Maes, R. Quian Quiroga, C. M. Van Rijn, and A. M. Coenen. "Enhanced Re-Habituation of the Orienting Response of the Human Event-Related Potential." Neuroscience Letters 356, 2 (2004): 103-106.

SAJJACHOLAPUnT, P., and L. J. BALL. "The Influence of Banner Advertisements on Attention and Memory: Human Faces with Averted Gaze can Enhance Advertising Effectiveness." Frontiers in Psychology 5, 166 (2014): 1-16.

SEVERn, J., G. E. Belch, and M. A. Belch. "The Effects of Sexual and Non-Sexual Advertising Appeals and Information Level on Cognitive Processing and Communication Effectiveness". Journal of Advertising 19, 1 (1990). doi: 10.1080/02650487.2016.1162344.

Schomaker, J., and B. C. WitTManN. "Memory Performance for Everyday Motivational and Neutral Objects is Dissociable from Attention." Frontiers in Behavioral Neuroscience, 11 (2017). doi: 10.3389/fnbeh.2017.00121.

SHELley, C. "Biomorphism and Models in Design." Philosophy and Cognitive Science II 20 (2015): 209-21.

Simion, C., and S. Shimojo. "Interrupting the Cascade: Orienting Contributes to Decision Making even in the Absence of Visual Stimulation." Perception \& Psychophysics 69, 4 (2007): 591-95.

Small, D. A., and N. M. VerrochI. "The Face of Need: Facial Emotion Expression on Charity Advertisements.” Journal of Marketing Research 46, 6 (2009): 777-87.

Smit, E., P. NeIJENS, and M. StuURman. "It's All about Catching the Reader's Attention." In International Advertising and Communication: Current Insights and Empirical Findings, S. Diehl, and R.Terlutter, eds. pp. 43-68, DUV, 2006. 
SoKolov, E. N. "The Orienting Response, and Future Directions of Its Development." Pavlovian Journal of Biological Science 25, 3 (1990): 142-150.

TOMALSKI, P., G. Csibra, and M. H. Johnson. "Rapid Orienting toward Face-Like Stimuli with Gaze-Relevant Contrast Information.” Perception 38, 4 (2009): 569-78.

TSAO, D. Y., and M. S. LiVingstone. "Mechanisms of Face Perception." Annual Review of Neuroscience 31 (2008): 411-37.

VAnRullen, R. "On Second Glance: Still no High-Level Pop-Out Effect for Faces." Vision Research 46, 18 (2006): 3017-3027.

WeAver, M. D., and J. LAuwereyns. "Attentional Capture and Hold: The Oculomotor Correlates of the Change Detection Advantage for Faces." Psychological Research 75, 1 (2011): 10-23.

XIAO, L., and M. DING. "Just the Faces: Exploring the Effects of Facial Features in Print Advertising." Marketing Science 33, 3 (2014): 338-52.

ZiMmER, H. "Habituation of the Orienting Response as Reflected by the Skin Conductance Response and by Endogenous Event-Related Brain Potentials." International Journal of Psychophysiology 60, 1 (2006): 44-58. 